\title{
Expression of IGF-II mRNA-binding proteins (IMPs) in gonads and testicular cancer
}

\author{
Niels A Hammer ${ }^{1}$, Thomas v O Hansen ${ }^{1}$, Anne Grete Byskov ${ }^{3}$, Eva Rajpert-De Meyts ${ }^{2}$, \\ Marie Louise Grøndahl ${ }^{4}$, Helle E Bredkjær ${ }^{4}$, Ulla M Wewer ${ }^{5}$, Jan Christiansen $^{6}$ and \\ Finn C Nielsen ${ }^{1}$ \\ Departments of ${ }^{1}$ Clinical Biochemistry, ${ }^{2}$ Growth and Reproduction and ${ }^{3}$ Laboratory of Reproductive Biology, \\ Women and Reproduction, Rigshospitalet, Blegdamsvej 9, DK-2100 Copenhagen, Denmark, ${ }^{4}$ Fertility Clinic, \\ Hvidovre Hospital, Kettegård Allé 30, DK-2650 Hvidovre, Denmark, ${ }^{5}$ Institute of Molecular Pathology, University \\ of Copenhagen, Frederik V's vej 11, DK-2100 Copenhagen, Denmark and ${ }^{6}$ Institute of Molecular Biology, \\ University of Copenhagen, DK-1307 Copenhagen, Denmark
}

Correspondence should be addressed to F C Nielsen; Email: fcn@rh.dk

\begin{abstract}
Insulin-like growth factor-II mRNA-binding proteins 1, 2 and 3 (IMP1, IMP2 and IMP3) belong to a family of RNA-binding proteins implicated in mRNA localization, turnover and translational control. We examined their expression pattern during development of murine and human testis and ovaries. In the mouse, IMPs were expressed in male and female gonadal cells at embryonic day 12.5 (E12.5). From E16.5, IMP1 and IMP3 became restricted to the developing germ cells, whereas IMP2 expression persisted in the interstitial cells. In mature mouse and human ovaries, IMP1, IMP2 and IMP3 were detected in resting and growing oocytes and in the granulosa cells. In testis, IMP1 and IMP3 were found mainly in the spermatogonia, whereas IMP2 was expressed in the immature Leydig cells. Moreover, all three IMPs were detected in human semen. The developmental expression pattern of IMP1 and IMP3 in the human testis prompted us to examine their possible involvement in testicular neoplasia. IMPs were detected primarily in germ-cell neoplasms, including preinvasive testicular carcinoma in situ, classical and spermatocytic seminoma, and nonseminomas, with particularly high expression in undifferentiated embryonal carcinoma. The relative expression of IMP1, IMP2 and IMP3 varied among tumor types and only IMP1 was detected in all carcinoma in situ cells. Thus IMPs, and in particular IMP1, may be useful auxiliary markers of testicular neoplasia.
\end{abstract}

Reproduction (2005) 130 203-212

\section{Introduction}

Translational control and mRNA localization are important mechanisms for control of gene expression in germ cells and during early embryogenesis. Posttranscriptional control is governed by RNA-binding proteins, several of which have been implicated in mammalian fertility (Ruggiu et al. 1997, Chennathukuzhi et al. 2003). The insulin-like growth factor-II (IGF-II) mRNA-binding proteins IMP1, IMP2 and IMP3 belong to a conserved family of mRNA-binding proteins consisting of two RNA-recognition motifs (RRMs) and four K-homology (KH) domains (Fig. 1a; Nielsen et al. 2001, Yaniv \& Yisraeli 2002, Yisraeli 2005). IMP1 is orthologous to the chicken zipcode-binding protein 1 (ZBP1) and the mouse $\mathrm{c}-m y c$ coding region determinant-binding protein (CRD-BP), that associate with $\beta$-actin and c-Myc mRNA, respectively (Ross et al. 1997, Doyle et al. 1998). IMP3 is closely related to $\mathrm{Vg} 1-\mathrm{RBP} / \mathrm{Vera}$, which mediates localization of the transforming growth factor- $\beta$-like factor
Vg1 mRNA to the vegetative pole during stages III and IV of Xenopus oocyte development and are important for mesoderm induction and left-right axis formation (Deshler et al. 1998, Havin et al. 1998, Zhang et al. 1999b). During mouse embryogenesis, IMP transcripts have been detected in the early zygote and later a sharp increase in the expression is seen around embryonic day 12.5 (E12.5) (Nielsen et al. 1999, Runge et al. 2000). At E12.5, IMP1 and IMP3 are mainly present in brain, limb-buds and in the epithelia of most organs (Mueller-Pillasch et al. 1999, Nielsen et al. 1999, Hansen et al. 2004). Moreover, high levels are expressed in the placenta and liver parenchyme (Leeds et al. 1997, Nielsen et al. 1999). Near the end of mouse embryogenesis IMP1 and IMP3 expression have almost disappeared (Mueller-Pillasch et al. 1999, Hansen et al. 2004). IMP1, IMP2 and IMP3 expression have, in general, not been reported in adult tissues, with a notable exception 


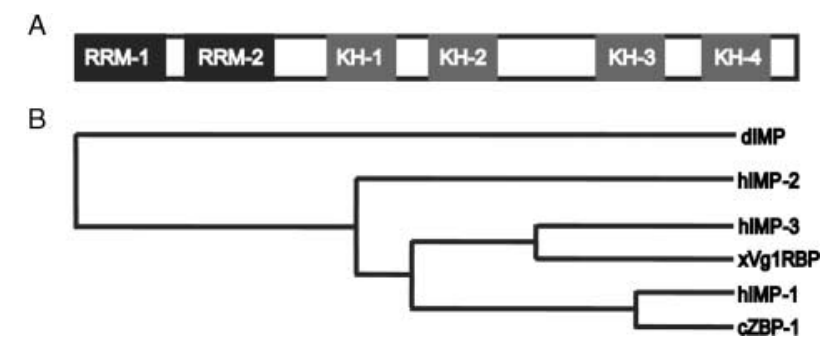

Figure 1 IMP structure and phylogenetic relationships. (A) Schematic representation of IMP structure, showing the two RNA-recognition motifs (RRMs) and the four K-homology domains (KHs). (B) Phylogenetic relationships between IMP and para- and orthologues (Drosophila, dIMP; human, hIMP; Xenopus, xVg1RBP; chicken, cZBP1).

of the testis, where both IMP1 and IMP3 mRNAs have been described (Mori et al. 2001, Wang et al. 2003).

To begin to characterize the expression pattern of the mammalian IMPs in gonads, we examined their cellular distribution in developing and mature ovaries and testis from mice and humans. Moreover a series of human testicular cancers, in particular those derived from germ cells, were analysed. As reported here, we established that IMPs are differentially expressed during gonadal development and with gender differences. Moreover, in the testis IMP1 and IMP3 are germ-cell specific, whereas IMP2 appears to be expressed primarily in Leydig cells.

\section{Materials and Methods}

\section{Human and mouse material}

The use of human tissue samples for the study of novel genes expressed in germ-cell cancer was approved by the Regional Committee for Medical Research Ethics in Denmark. A series of six normal fetal gonads (four testicular specimens and two ovaries) from tissue archives of the Copenhagen University Hospital were included. The specimens were obtained after induced or spontaneous abortions and stillbirths, mainly due to placental or maternal problems. Normal adult gonads (three testis and two ovaries), and a series of 33 testicular neoplasms, including preinvasive carcinoma in situ (CIS), classical seminomas, various non-seminomatous tumour components, spermatocytic seminoma, as well as non-germ-cell-derived Leydig cell tumours and a testicular B-cell lymphoma, were also analysed. The human tissue samples from adults with testicular neoplasms were obtained directly after orchidectomy and macroscopic pathological evaluation. Each sample was divided into several tissue fragments, which were either frozen or fixed overnight at $4{ }^{\circ} \mathrm{C}$ in buffered formalin/paraformaldehyde and embedded subsequently in paraffin. The human semen used was surplus from in vitro fertilization.

Mouse gonads were obtained from B6/D2-F1 mice. E11.5 days post coitus (copulatory plug termed E0.5), E12.5, E14.5 and E16.5, and gonads from 14-day-old and adult animals were used. The gonads were removed and fixed in $4 \%$ paraformaldehyde before paraffin embedding, or processed for
Western-blot analysis. For production of oocytes, zygotes and blastocysts, mice were hyperstimulated intraperitoneally with Menopur containing $15 \mathrm{IU}$ follicle-stimulating hormone and $15 \mathrm{IU}$ luteinizing hormone (Ferring, Lausanne, Switzerland) and $40 \mathrm{~h}$ later either decapitated followed by oocyte extraction from the ovaries, or stimulated with $5 \mathrm{IU}$ human chorionic ganadotropin (Organon, Roseland, NJ, USA) and caged with a male $4 \mathrm{~h}$ later, overnight. Zygotes were extracted from the oviduct the day after the plug and blastocysts from the oviduct 3 days later.

\section{Immunohistochemistry}

Polyclonal anti-IMP1 antibody raised against full-length IMP1, and monospecific anti-IMP2 and anti-IMP3 antibodies directed toward the C-terminus of the proteins, were produced as described previously (Nielsen et al. 1999). The tissues were serially sectioned at $4 \mu \mathrm{m}$, deparaffinized by immersion in xylene for 10 and subsequently $5 \mathrm{~min}$, and rehydrated in ethanol. Antigens were retrieved by boiling in $10 \mathrm{mM}$ citric acid ( $\mathrm{pH}$ 6.0). Sections were preabsorbed with TBS (0.05 M Tris/HCl (pH 7.6), 0.15 M NaCl and 0.01\% Triton $\mathrm{X}-100)$ containing $10 \%$ pig serum (DakoCytomation, Glostrup, Denmark) for 20 min, before they were incubated for $1 \mathrm{~h}$ with primary antibody diluted 1:2000 in TBS containing $10 \%$ pig serum. For control sections the specific antibody was omitted. Moreover, the peptide specific-antibodies were preabsorbed with the peptide that was used for the immunizations. Following rinses at $5 \mathrm{~min}$ intervals in TBS, the sections were incubated with EnVision + horseradish peroxidase-conjugated secondary antibody (DakoCytomation), rinsed and stained with EnVision + liquid diamidobensidine solution (DakoCytomation) for $5 \mathrm{~min}$. Sections were dehydrated in ethanol, coverslips added using Pertex (Histolab, Gothenburg, Sweden) and viewed through a TE300 eclipse Microscope (Nikon, Japan). To avoid overstaining of E12.5 gonads, a horseradish-conjugated swine anti-rabbit (DakoCytomation) secondary antibody was used instead of EnVision +, followed by diaminobensidine solution, made from tablets (Sigma).

Fluorescent immunohistochemistry on human fetal testis included a tyramid amplification system, where the secondary antibody was replaced with biotin-conjugated secondary antibody (DakoCytomation), and the sections were incubated with Vectastain ABC complex (Vector Laboratories, Burlingame, CA, USA) for $45 \mathrm{~min}$, tyramid signal amplification (Perkin Elmer, Boston, MA, USA) for 12 min, and finally Cy2-conjugated streptavidin (Jackson ImmunoResearch, West Grove, PA, USA) for $20 \mathrm{~min}$, before mounting in nonfading glycerol medium (DABCO). Repeated rinses were performed between each step. Specimens were viewed on a LSM 510 confocal laser scanning microscope (Zeiss, Oberkochen, Germany).

Blastocysts and oocytes were fixed in $4 \%$ formaldehyde for 15 min, washed in PBS, and permeabilized in 1\% Triton $\mathrm{X}-100$ solution in PBS for $1 \mathrm{~h}$. Blocking was performed with $10 \%$ swine serum in PBS for $1 \mathrm{~h}$, and incubation proceeded 
in blocking solution containing primary antibody diluted 1:2000 overnight at $4{ }^{\circ} \mathrm{C}$. The blastocysts and oocytes were washed with $0.5 \%$ Triton X-100 in PBS and placed in tetramethylrhodamine $\beta$-isothiocyanate (TRITC) secondary antibody (Jackson ImmunoResearch) diluted 1:100 for $2 \mathrm{~h}$ at room temperature. After washing, the blastocysts and oocytes were mounted in antifading media, covered with glass slips and viewed as described above.

Semen was smeared on superfrost + (Menzel-Glaser, Braunschweig, Germany) slides, left to dry and fixed in ice-cold methanol $\left(-20^{\circ} \mathrm{C}\right)$ for $10 \mathrm{~min}$. Semen smears were blocked, incubated with primary antibody and incubated with Envision + secondary antibody as described above. Finally Cy2-conjugated anti-horseradish peroxidase (Jackson ImmunoResearch), diluted 1:100, was applied for $30 \mathrm{~min}$, and, following repeated rinses, slides had coverslips added and were viewed as described above.

\section{Western-blot analysis}

Western-blot analysis was performed as described (Nielsen et al. 1999). Briefly, protein extracts from mouse gonads, oocytes and blastocysts, and human semen, were separated in 10\% SDS/polyacrylamide gels and transferred to Hybond-P membranes (Amersham Pharmacia Biotech, Little Chalfont, Buckinghamshire, UK). After blocking, membranes were incubated with anti-IMP1, anti-IMP2, anti-IMP3 or anti-tubulin (Sigma) antibodies in blocking solution at $4{ }^{\circ} \mathrm{C}$ overnight, followed by horseradish peroxidase-conjugated anti-rabbit IgG (Transduction Laboratories, San Jose, USA) for $1 \mathrm{~h}$ at room temperature. Immunoreactive proteins were detected with Supersignal chemiluminescence reagents (Pierce, Rockford, IL, USA) according to the manufacturer's instructions.

\section{RNA analysis}

Total RNA from a range of adult organs, as well as fetal liver and placenta were obtained from Clontech (Mountain View, CA, USA), whereas total RNA from adult mice gonads was isolated with Trizol reagent (Invitrogen, Carlsbad, CA, USA). Quantitative reverse transcription (RT)-PCR was performed using the LightCycler-FastStart DNA Master SYBR Green I kit (Roche, Mannheim, Germany) according to the manufacturer's instructions. Primer sequences for the examined genes were as follows: Imp1, 5'-CAAGCAGCAGCAAGTGGACA-3' and 5'-TGGAGTGCACACTGATGGCTT3'; Imp2 and Imp2s, 5'-CCAGTGCTGAGATAGAGATT-3' and $5^{\prime}$ GCTCTGGATAAGAGTGATGA-3'; Imp3, 5'-CCAAAGCTGAGGAGGAGATC-3' and $5^{\prime}$-GGAGGAGTCATGGCTGAAGG-3'. The number of transcript copies per $\mu \mathrm{g}$ total RNA from each tissue were calculated from standard curves of amplified full-length cDNA (Nielsen et al. 1999). All experiments were performed three times and the results were expressed as means \pm S.D.

Multiplex RT-PCR was performed using a standard multiplex PCR kit (Qiagen, Valencia, CA, USA) with $25 \mu \mathrm{l}$ master mix, $5 \mu \mathrm{l}$ primer mix, $15.5 \mu \mathrm{l}$ water, $2.5 \mu \mathrm{l} \mathrm{Q}$ solution and $2 \mu \mathrm{l}$ cDNA. The primers used were: $5^{\prime}$-TCTAACCGGGAGCAGACCAG- $3^{\prime}$ and 5'-CTGCGTAGGCACCAGGAGCC-3' resulting in a 237 bp Imp 1 fragment; 5'-GTTGGATGGGCTGTTGGCTGAATATGG-3' and 5'-GTGAAGGAGAGCTCACCTCTTCATCG-3' resulting in a 213 bp Imp2 fragment; 5'-CAAATTGTACATCGGGAACCTCAGC- $3^{\prime}$ and $5^{\prime}$-CTTCCATCGGTTTCCCATCTAGTTCC-3' resulting in a 203 bp Imp3 fragment; and 5'-ACTGGGACGACATGGAGAAG-3' and 5'-GGGGTGTTGAAGGTCTCAAA- ${ }^{\prime}$ 'resulting in a $157 \mathrm{bp} \beta$-actin fragment. Cycling conditions were: one cycle at $95^{\circ} \mathrm{C}$ for $15 \mathrm{~min}$, followed by 28 cycles of $94^{\circ} \mathrm{C}$ for $30 \mathrm{~s}$ and $60^{\circ} \mathrm{C}$ for $90 \mathrm{~s}$, followed by $72{ }^{\circ} \mathrm{C}$ for $90 \mathrm{~s}$. Products were run on a $2 \%$ ethidium bromidestained agarose gel, and bands were visualized using a Gel Doc 1000 system (Bio-Rad, Hercules, CA, USA).

\section{Results}

\section{IMP mRNA expression in adult human organs and mouse gonads}

To screen for the expression of IMPs in adult human tissues we isolated total RNA from a series of organs and determined the amount of IMP1, IMP2 and its splice variant IMP2 $\Delta$, as well as, IMP3 mRNA by quantitative RTPCR analysis (Fig. 2A). For comparison, fetal liver and placenta, that express all three IMPs (Leeds et al. 1997, Nielsen et al. 1999) were also included in the analysis. IMP1 mRNA was detected in kidney, prostate, trachea and testis, whereas IMP3 mRNA was detected in ovaries, testis and brain. IMP1 and IMP3 mRNA expression levels in the testis were comparable to fetal liver and placenta. In contrast, moderate levels of IMP2 and IMP2 $\Delta$ transcripts were detected in many adult human tissues and in particular in the bone marrow, colon, kidney, salivary gland and the testis. To confirm IMP mRNA expression in mouse gonads, multiplex RT-PCR of adult mouse cDNA was performed, and this showed that all three IMPs were expressed in both testis and ovaries (Fig. 2B).

\section{IMP1, IMP2 and IMP3 in developing and mature mouse and human gonads}

To characterize the cellular distribution of gonadal IMP during mouse development, immunohistochemistry was performed on sections from fetal gonads retrieved at E11.5, E12.5, E14.5, E16.5 and from postnatal day 14 and adult gonads.

At E12.5 mouse IMP1, IMP2 and IMP3 immunoreactivity was ubquitous in both male and female gonads as demonstrated by immunohistochemistry (Fig. 3A) and Western blotting (Fig. 3B). The picture was similar at E14.5 (data not shown), but from E16.5, IMP1 and IMP3 became restricted to the developing germ cells, whereas IMP2 expression remained ubiquitous (Fig. 3C). In human fetal ovaries from 32 weeks of gestation, developing follicles exhibited strong IMP3 and weak IMP1 immunoreactivity, whereas IMP2 

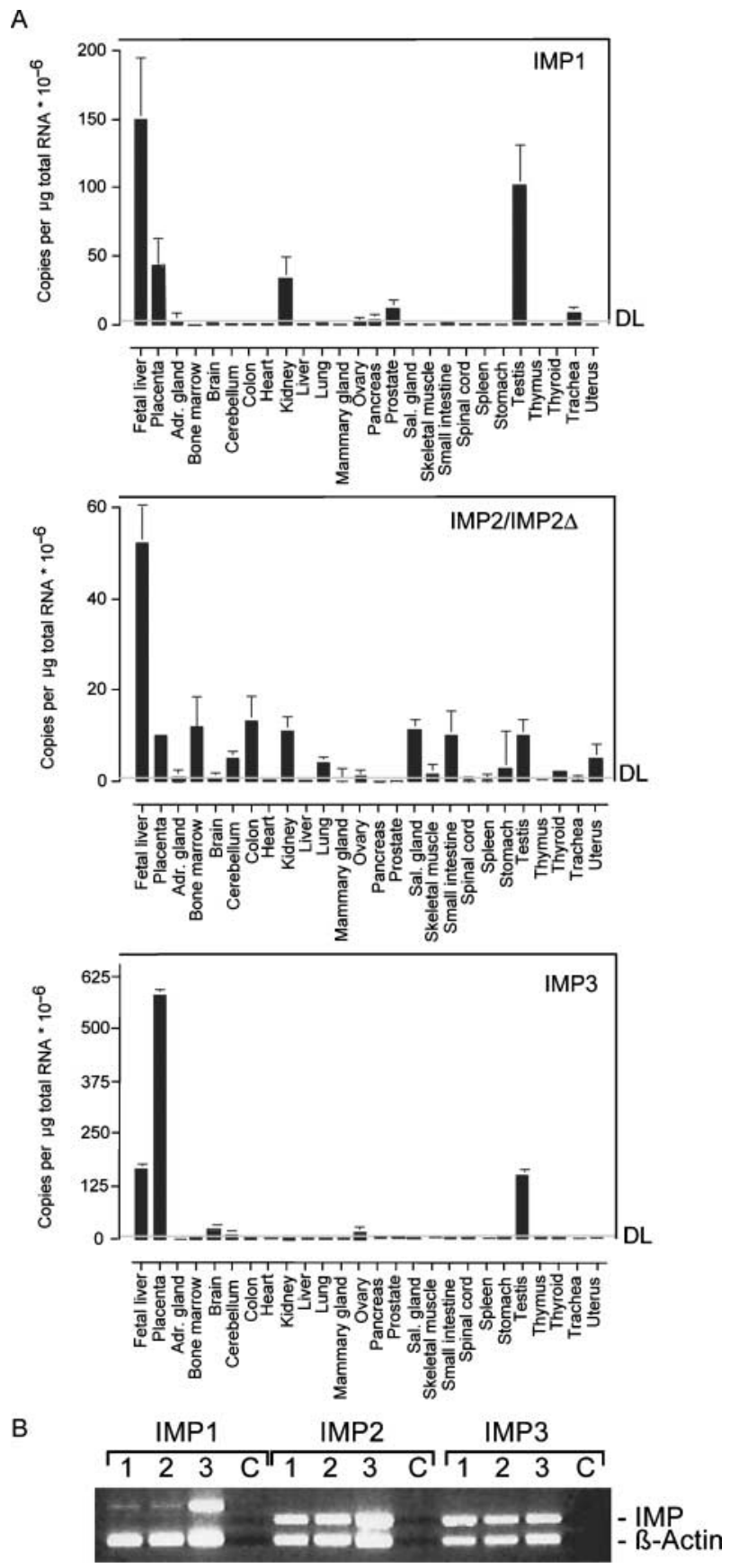

Figure 2 IMP mRNA in adult human organs and mice gonads. (A) Quantitative real-time PCR of IMP1, IMP2/IMP2 $\Delta$ (splice variant) and IMP3 mRNA in adult human organs. Fetal liver and placenta are included for comparison. DL, detection limit; Adr., adrenal; Sal., salivary. (B) RNAs from adult mouse testis (lanes 1), ovary (lanes 2) and E12.5 (lanes 3) were examined by multiplex RT-PCR using specific primers for IMP1, IMP2, IMP3 and $\beta$-actin transcripts. $C$ indicates the negative control without template cDNA. The products were separated by agarose gel electorphoresis and visualized by ethidium bromide staining.

expression was ubiquitous (Fig. 3D). In developing testis at 16, 24, 38 and 40 weeks of gestation (only 38 week gestation is shown), the gonocytes stained positive for all three IMPs, whereas IMP2 immunoreactivity also was found in the interstitial tissue (Fig. 3D).

In adult mouse and human ovaries (Fig. 4A and 4B, respectively) all three IMPs stained the cytoplasm of both resting and growing oocytes. Furthermore, IMP2 staining, and to a lesser degree IMP1 and IMP3 staining, was seen in the granulosa cells of small and growing follicles.

In adult mouse testis, IMP1 staining was observed selectively in a subpopulation of the spermatogonia, where one or two cells stained positive in each tubular cross-section. IMP2 was present in elongated spindle-shaped interstitial cells, which likely represents immature Leydig cells, whereas IMP3 was expressed in all spermatogonia and in spermatocytes (Fig. 4A). Serial sectioning showed that the strongest IMP3 staining was observed in the subpopulation of IMP1-positive spermatogonia (data not shown). IMP1 expression was further substantiated by demonstration of $\beta$-galactosidase activity in the spermatogonia of IMP1 $1^{+/-}$ mice exhibiting a $\beta$-galactosidase cassette under control of the endogenous Imp1 promoter (Hansen et al. 2004). In agreement with the immunohistochemical data, $\beta$-galactosidase activity was present in the peripheral spermatogonia of the tubuli (data not shown). IMP staining in adult human testis was similar to that of mouse testis but with some differences. IMP1 was found in nearly all spermatogonia, IMP2 in Leydig cells and in a few spermatogonia, whereas IMP3 was primarily found in spermatogonia and to a lesser extent in spermatocytes (Fig. 4B). However, as shown in Fig. 4C, we noted a difference in the subcellular localization of IMP3, since human IMP3 staining was found in both the nucleus and the cytoplasm of the spermatogonia, whereas mouse IMP3 was clearly enriched in the cytoplasm.

\section{IMP expression in mouse oocytes and blastocysts and in human semen}

To characterize the expression of IMPs after ovulation, we collected oocytes and blastomeres ( $3-5$ days) from hyperovulated mice. Oocytes exhibited a strong cytoplasmic staining with a granular appearance of all three IMPs (Fig. 5A). There were no signs of cytoplasmic polarization and the expression persisted from pre-fertilization to the blastocyst stage (Fig. 5A and 5C). By Western blot analysis all IMPs were detected in mouse zygotes and blastocysts (Fig. 5b).

To examine for the presence of IMP in semen, spermatozoa were isolated and lysed before Western-blot analysis was performed (Fig. 5D). Full-length ( $69 \mathrm{kDa})$ IMP1, IMP2 and IMP3 were all found enriched in the rinsed semen, whereas only low levels of the proteins were detected in the raw semen and in the supernatant. In the supernatant, we observed a $\sim 50 \mathrm{kDa}$ band, which most likely represents a degradation product containing the four $\mathrm{KH}$ domains. Immunohistochemical staining of human semen showed IMP3 and to a lesser degree IMP2 (data not shown) in the connecting piece and the tail of the spermatozoa (Fig. 5E), whereas no IMP1 signal was detected. 
A Mouse E12.5

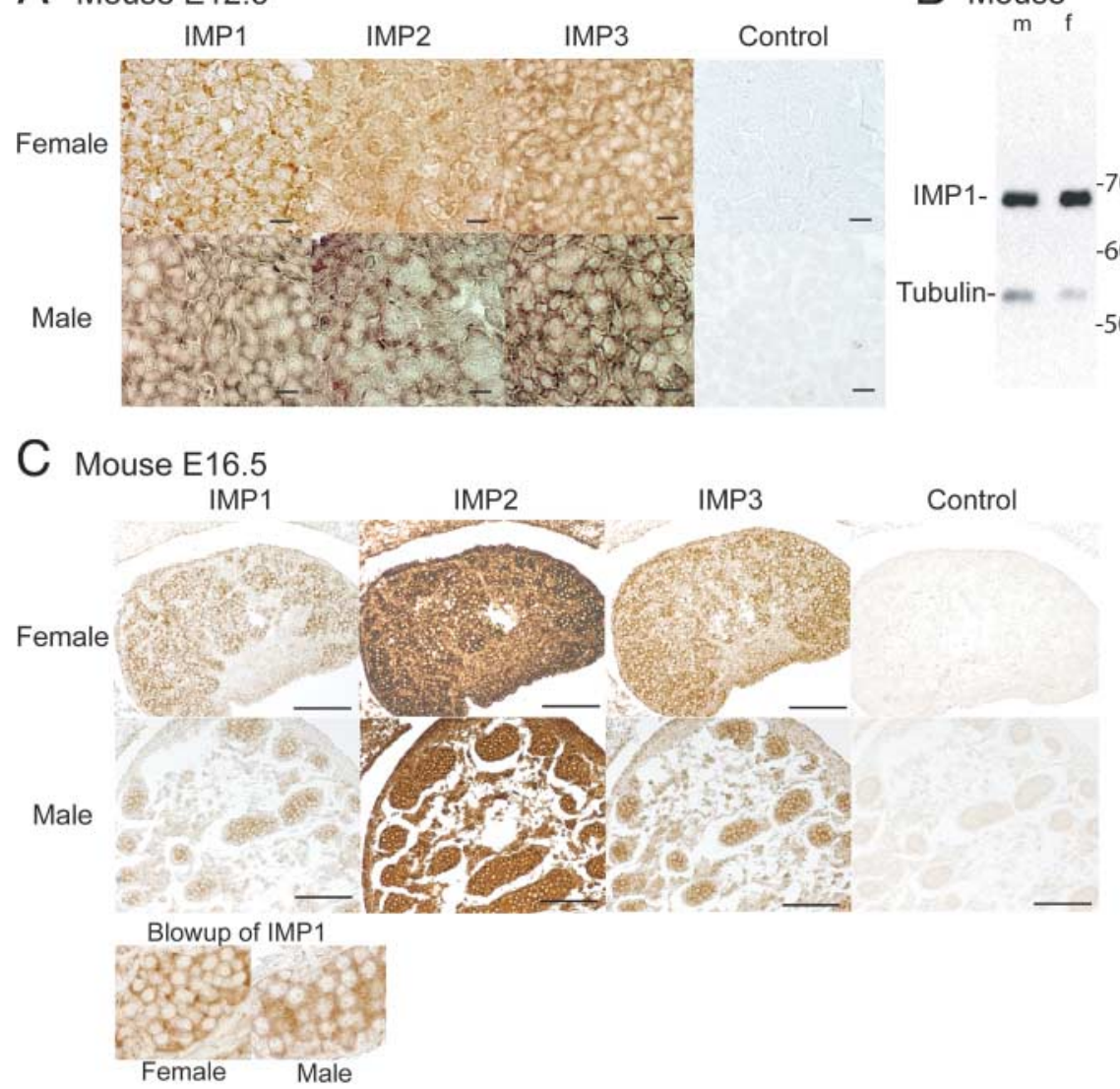

D Human

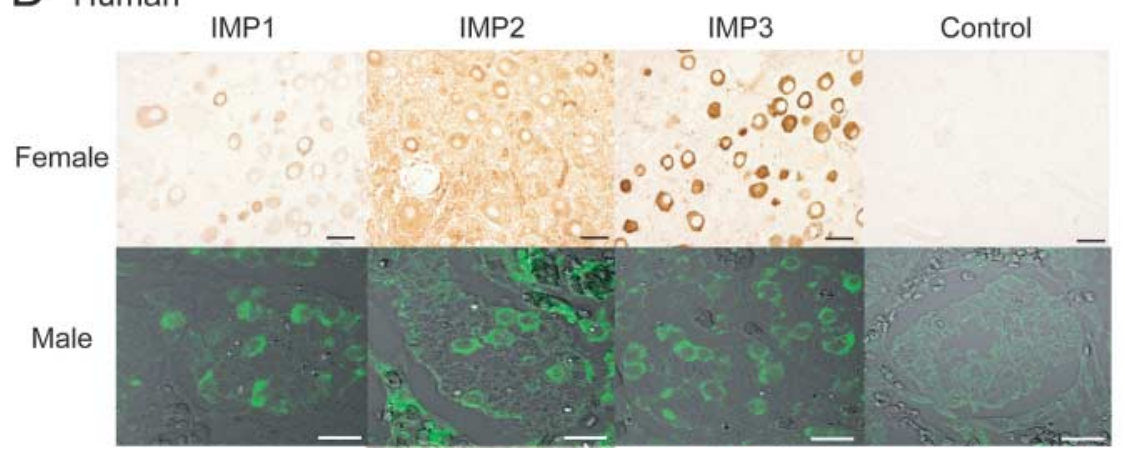

Figure 3 IMP immunostaining of mouse and human embryonic gonads. (A) Sections from female and male E12.5 mouse gonads stained with anti-IMP1, anti-IMP2 or anti-IMP3 antibody, and a representative blocking control on the right. Scale bars, $20 \mu \mathrm{m}$. (B) Western blot with anti-IMP1 on male $(\mathrm{m})$ and female (f) gonads on E12.5, with tubulin as a loading control. (C) Sections from female and male E16.5 mouse gonads stained with anti-IMP1, anti-IMP2 or anti-IMP3 antibody, with the negative control on the right. Scale bars, $100 \mu \mathrm{m}$. (D) Immunohistochemical staining with anti-IMP1, anti-IMP2 or anti-IMP3 antibody on human fetal ovaries (32 weeks gestation) and human testis (38 weeks gestation). Negative control is shown on the right. Scale bars: ovary, $50 \mu \mathrm{m}$; testis, $20 \mu \mathrm{m}$.

\section{IMP in testicular cancer}

We next addressed the question whether IMPs play any role in testicular oncogenesis, especially since most germcell tumours display a close similarity to immature gonocytes and their precursor cell, CIS, retains embryonic phenotypic features (Skakkebaek et al. 1987, Rajpert-De Meyts et al. 2003b). We examined the expression of IMP1, IMP2 and IMP3 in a series of primarily germ-cellderived neoplasms, which are the most common among testicular tumours, including pre-invasive CIS, classical seminoma, embryonal carcinoma, teratoma and spermatocytic seminoma. In addition, a few tumours derived from somatic testicular cells were examined, including Leydig cell tumour and testis B-cell lymphoma. Immunoreactive
IMP1, IMP2 or IMP3 were found in all tumours, but a marked variation in the expression pattern of the proteins was noted (Fig. 6A). Abundant expression of IMP1 was seen in all CIS cells, whereas IMP2 and IMP3 expression was seen only in a subset of CIS cells. IMP1, IMP2 and IMP3 were expressed in the majority of the other tumours, whereas only IMP2 expression was found in the Leydig and B-cell tumours (Fig. 6B).

\section{Discussion}

Here we report the characterization of the developmental expression pattern of the three members of the IMP family in murine and human gonads and in human testicular 


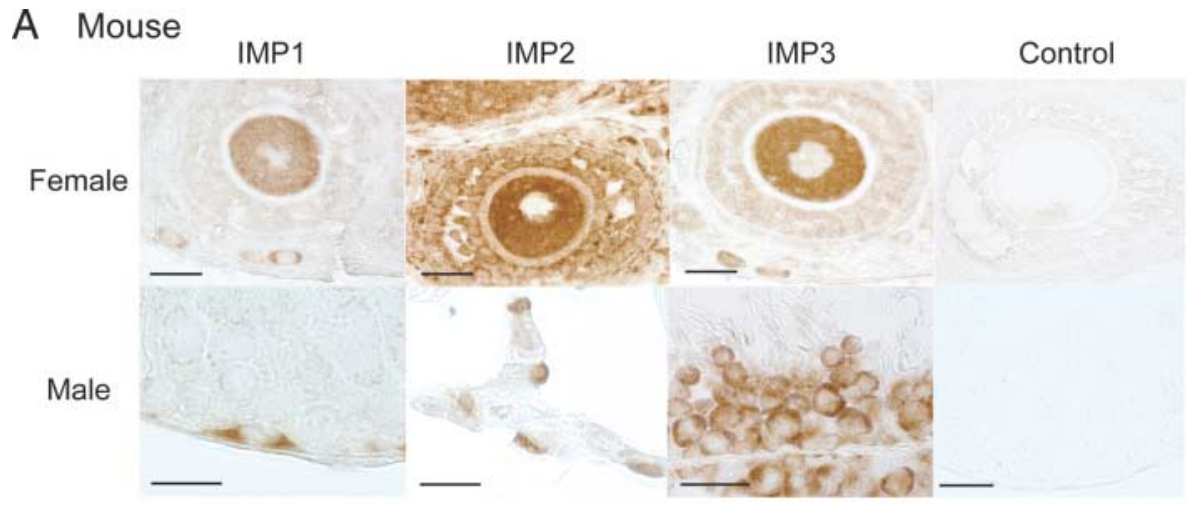

B Human

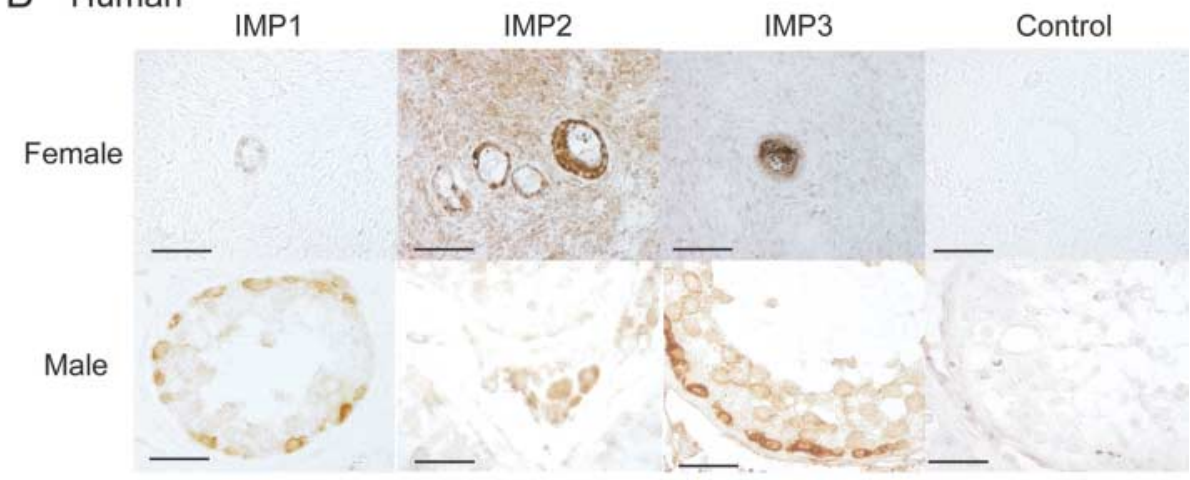

C Human

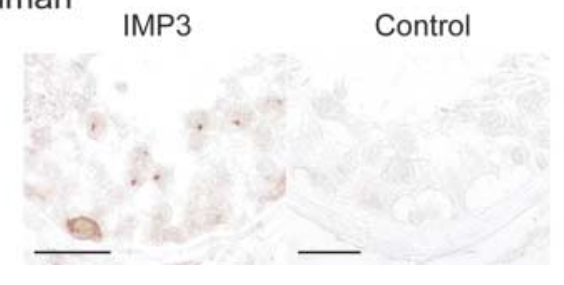

Figure 4 IMP expression in adult mouse and human gonads. (A) Immunohistochemical staining of sections from adult mouse gonads with anti-IMP1, antiIMP2 or anti-IMP3 antibody, and a representative blocking control on the right. (B) Immunohistochemical staining of sections from adult human gonads with anti-IMP1, anti-IMP2 or anti-IMP3 antibody, and a representative blocking (male) or negative (female) control on the right. (C) Staining of sections from adult human testis using anti-IMP3 antibody, and an IMP3 blocking control on the right. Note that both cytoplasmatic and nuclear IMP3 staining was observed. Scale bars, $20 \mu \mathrm{m}$. neoplasms. The data indicate that the IMPs may play a biological role in germ-cell development and maturation, which is in agreement with the essential roles of RNA trafficking and translational control of transcripts of a number of germ-cell-specific genes (Schumacher et al. 1995, Ruggiu et al. 1997, Chennathukuzhi et al. 2003, Yang et al. 2003).

IMP1, IMP2 and IMP3 were originally discovered in embryos and in transformed cells (Mueller-Pillasch et al. 1999, Nielsen et al. 1999, Zhang et al. 1999a). Although the fetal expression is prominent, data indicating that the proteins are also present in mature tissues have been accumulating (Mori et al. 2001, Gu et al. 2004, Hansen et al. 2004). Adding to the previous data, we found that IMP1 mRNA was present in adult human kidneys, prostate, testis and ovaries, and IMP3 mRNA was found in brain, testis and ovaries, whereas IMP2 mRNA was more widespread but at low levels of expression. From a phylogenetic point of view, this may be expected, since IMP1 and IMP3 are closely related, whereas IMP2 diverged from the two other members at an earlier stage and may have acquired a distinct pattern of expression (Fig. 1B).

As it was immediately apparent that IMP1 and IMP3 mRNAs were abundant in the testis and almost comparable to fetal levels, we investigated their expression pattern at the protein level during gonadal development. Mouse gonads arise from the bilateral genital ridges, and molecular differences between male and female gonads can be detected at E11.5. Morphological differences between developing ovaries and testis are apparent at E12.5, coinciding with the presence of the IMPs (Nielsen et al. 1999). At E12.5 all three IMP proteins were expressed ubiquitously in the developing gonads. Expression of IMP1 and IMP3 becomes restricted to germ cells at E16.5. In the male germ line, further maturation results in the restriction of IMP1 expression to a small subpopulation of adult spermatogonia, whereas IMP3 expression remains in all spermatogonia. The IMP1-positive spermatogonia most probably represent the $A$ (stem)-spermatogonia, which in 
A

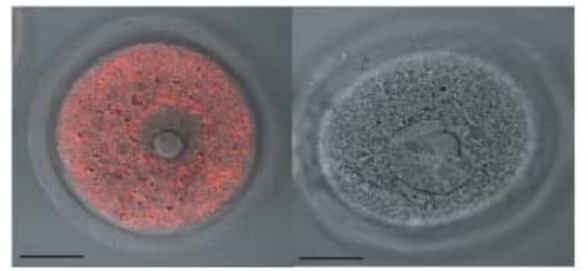

B

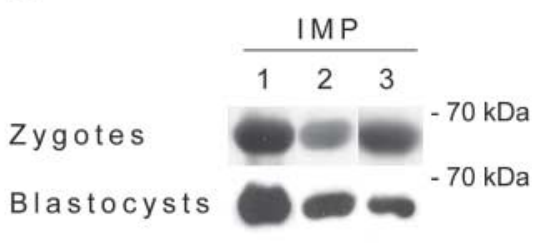

C

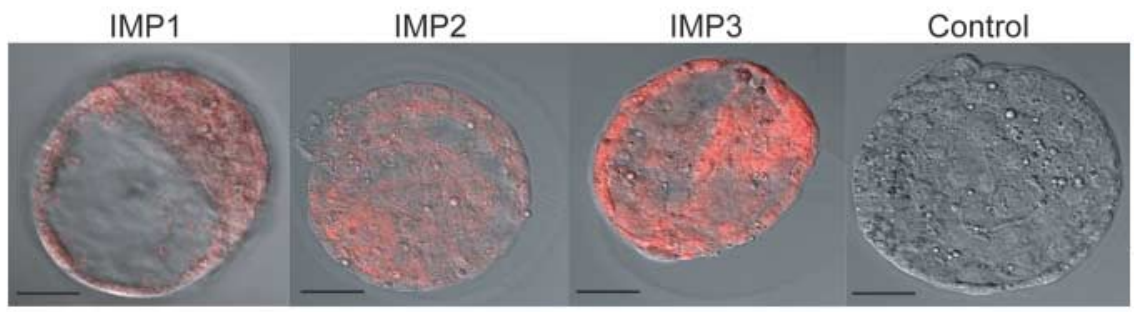

D

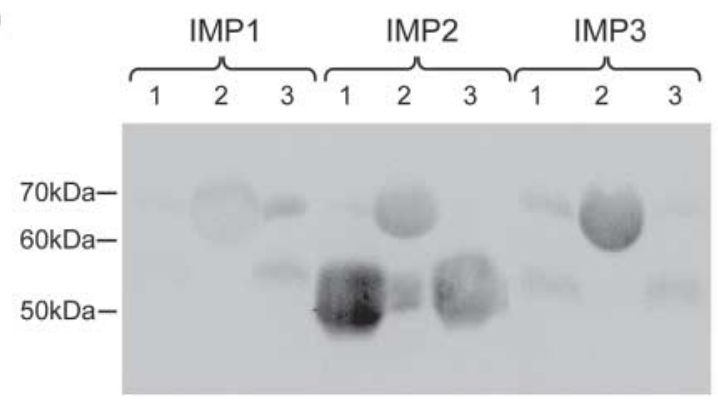

E

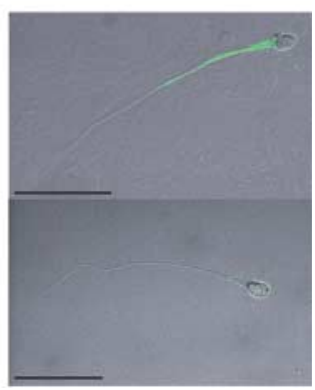

Figure 5 IMP expression in mouse oocytes and blastcysts and in human semen. (A) Immunohistochemical staining of a mouse oocyte using anti-IMP2 antibody. Negative control is shown on the right. Scale bar, $30 \mu \mathrm{m}$. (B) Westernblot analysis of 3-5-day-old mouse zygotes and blastocysts using anti-IMP1, anti-IMP2 or anti-IMP3 antibody. (C) Immunohistochemical staining of mouse blastocyst with anti-IMP1, antiIMP2 or anti-IMP3 antibody. Negative control is shown on the right. Scale bar, $30 \mu \mathrm{m}$. (D) Western-blot analysis on human raw semen (lanes 1 ), rinsed semen (lanes 2) or supernatant (lanes 3) using anti-IMP1, anti-IMP2 or anti-IMP3 antibody. (E) Immunohistochemical staining of spermatozoa with anti-IMP3 antibody (top panel), and a negative control (bottom panel). Scale bar, $20 \mu \mathrm{m}$. mouse retain a high expression of embryonic pluripotencysustaining factors, such as Oct-4 (Pesce et al. 1998).

Although the cellular location in the adult testis was similar in mice and humans, we noted that IMP3 immunoreactivity was also present in the nucleus of the human spermatogonia, whereas the staining in mice was most prominent in the cytoplasm. The significance of this difference is currently unclear, but IMPs exhibit multiple nuclear export signals. It is envisioned that IMPs are loaded onto their target mRNAs in the nucleus and that this event determines the cytoplasmic fate of the transcripts (Nielsen et al. 2003, Oleynikov \& Singer 2003). Similar to IMPs, testis brain RNA-binding protein (TB-RBP) contains a nuclear export signal. TB-RBP was described in the nuclei of pachytene spermatocytes and in the cytoplasm of diplotene/diakinesis spermatocytes and postmeiotic spermatids, and it has been proposed that the dynamic localization may be linked to the stagespecific export and release of target transcripts (Cho et al. 2004).

An important lead to the function of the IMPs originally came from studies of Xenopus Vg1 mRNA, which during early oogenesis becomes localized to the vegetative pole through interaction with the IMP3 orthologue Vg1-RBP (Weeks \& Melton 1987, Tannahill \& Melton 1989, Thomsen \& Melton 1993). The function is likely to differ in mammalian oocytes, where there is no obvious polarization. The granular appearance of the IMPs indicates that the proteins are present in large ribonucleoprotein complexes similar to those found in somatic cells (Nielsen et al. 2002). Vg1-RBP has recently been implicated in neural crest cell migration (Yaniv et al. 2003) and overexpression of IMP3/KOC in a transgenic mouse model was incompatible with a differentiated acinar phenotype and led to acinar-ductal metaplasia (Wagner et al. 2003). In this way, testicular IMP1 and IMP3 could play a role in maintaining the pool of spermatogonial stem cells or be implicated in germ-cell movement in the seminiferous epithelium during spermatogenesis. IMP1-deficient mice are, however, fertile (Hansen et al. 2004), but since IMPs are able to form homo- and heterodimers and known to associate with the same RNA targets (Nielsen et al. 2004), the proteins may be redundant. Mouse models deficient in more than one of the IMPs are underway to address these issues.

Several observations have indicated that IMPs may play a role in tumour development. IMPs are produced in various tumours (Yaniv \& Yisraeli 2002) and overexpression of mouse IMP1/CRD-BP in mammary duct epithelium led to malignant transformation of the cells (Tessier et al. 2004). The germ-cell tumours of young adults originate from the CIS cell, which is generally accepted as the 


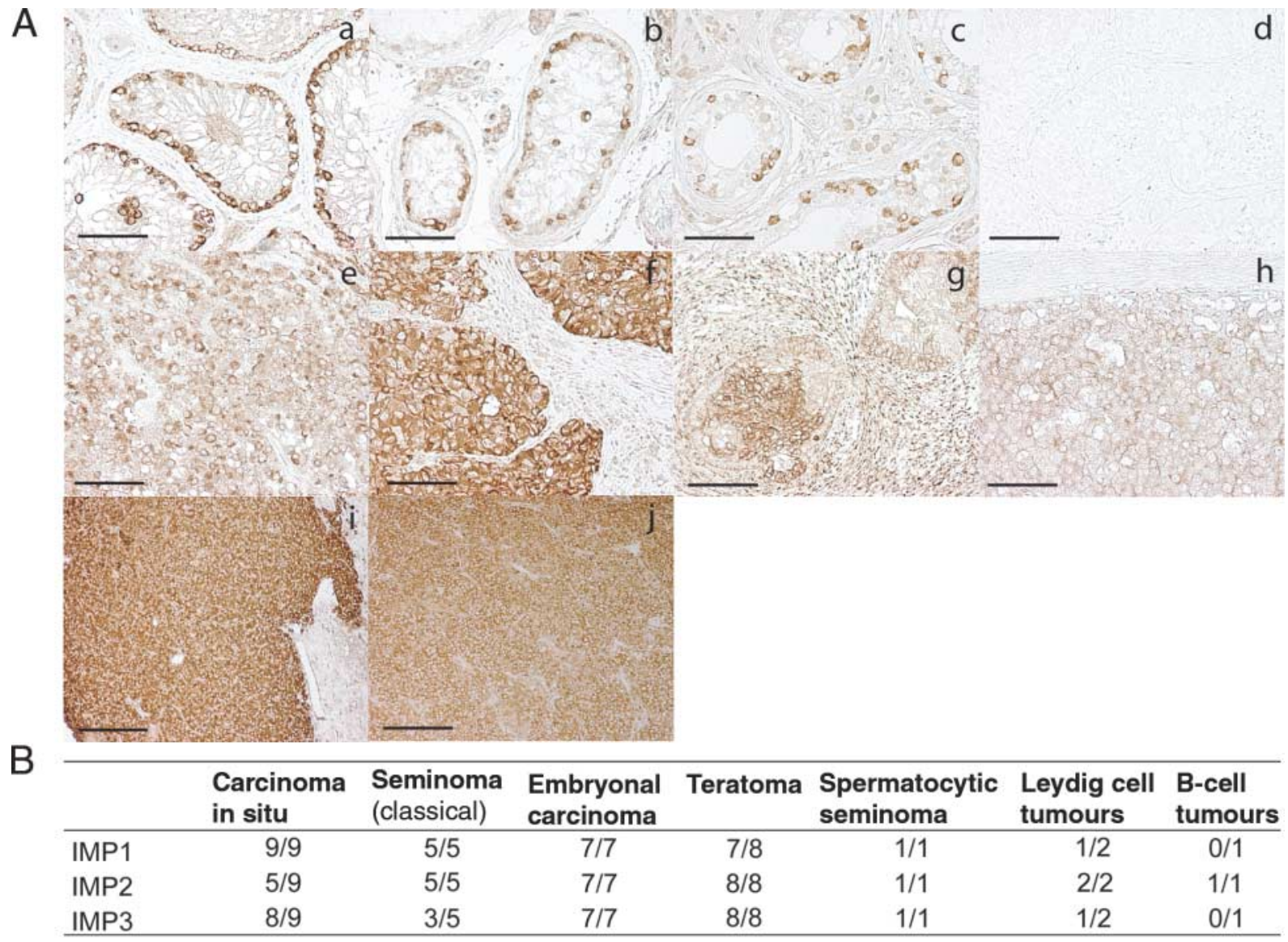

Figure 6 IMP expression in testicular cancer. (A) Immunohistochemical staining of human testis tumours. CIS cells stained with anti-IMP1, anti-IMP2 or anti-IMP3 antibody diluted 1:2000-10000 (a-c) or without specific antibody (d). Seminoma (classical) (e), embryonal carcinoma $(\mathrm{f})$, teratoma $(\mathrm{g})$ and spermatocytic seminoma $(\mathrm{h})$ stained with anti-IMP1 antibody diluted 1:2000; Leydig cell tumour (i), and testicular B-cell tumour (j) stained with anti-IMP2 antibody diluted 1:2000. Scale bars, $40 \mu \mathrm{m}$. (B) Summary of the stainings indicating the number of tumours with IMP1, IMP2 and IMP3 expression out of the total number of examined tumours.

precursor of all adult germinal cell cancers except spermatocytic seminoma. The CIS cells develop during fetal life and are considered as pluripotent malignant gonocytes with the capacity to either proliferate and invade as a seminoma or to regress into primitive embryonal cells and differentiate into a variety of histological forms (nonseminoma). The presence of IMPs in CIS supports the general view that the cells are derived from a common pre-invasive precursor of germ cells (Skakkebaek et al. 1987, Rorth et al. 2000). In the case of the spermatocytic seminoma, a rare germ-cell tumour of elderly men, we found only moderate expression of all three IMPs. This is consistent with the current understanding of the pathogenesis of this tumour, which is not derived from CIS but is believed to originate from mature adult spermatogonia (Rajpert-De Meyts et al. 2003a). The overall expression pattern of IMPs in testicular tumours, in particular the abundance of IMP1 both in CIS cells and embryonal carcinoma with a low expression in differentiated teratomas, is also consistent with the recently observed similarity in gene-expression signature between CIS cells and embryonic stem cells (Almstrup et al. 2004). Furthermore, due to their differential expression in testicular tumours, IMPs may have some value as auxiliary markers for pathologists, although they cannot be used as CIS markers because of the presence in normal spermatogonia.

In conclusion, we report the expression of IMPs in developing gonads and in mature testicular germ cells and oocytes. Moreover, the differential expression of IMPs in testicular germ-cell neoplasms, including CIS, provides additional support for their histogenesis.

\section{Acknowledgements}

We thank Niels Graem for fetal testis sections and Joan Christiansen, Pernille Ekstrøm, Inga Husom and Tiny Roed for technical assistance. This work was supported by the Danish Medical and Natural Science Research Councils, the Neye Foundation, the Novo Nordisk Foundation, the Toyota Foundation, the Danish Cancer Society and the Danish Hospital 
Foundation for Medical Research, Region of Copenhagen, The Faroe Islands and Greenland.

\section{References}

Almstrup K, Hoei-Hansen CE, Wirkner U, Blake J, Schwager C, Ansorge W, Nielsen JE, Skakkebaek NE, Rajpert-De Meyts E \& Leffers H 2004 Embryonic stem cell-like features of testicular carcinoma in situ revealed by genome-wide gene expression profiling. Cancer Research 64 4736-4743.

Chennathukuzhi V, Stein JM, Abel T, Donlon S, Yang S, Miller JP, Allman DM, Simmons RA \& Hecht NB 2003 Mice deficient for testis-brain RNA-binding protein exhibit a coordinate loss of TRAX, reduced fertility, altered gene expression in the brain, and behavioral changes. Molecular and Cellular Biology 23 6419-6434.

Cho YS, Chennathukuzhi VM, Handel MA, Eppig J \& Hecht NB 2004 The relative levels of translin-associated factor X (TRAX) and testis brain RNA-binding protein determine their nucleocytoplasmic distribution in male germ cells. Journal of Biological Chemistry 279 31514-31523.

Deshler JO, Highett MI, Abramson T \& Schnapp BJ 1998 A highly conserved RNA-binding protein for cytoplasmic mRNA localization in vertebrates. Current Biology 8 489-496.

Doyle GA, Betz NA, Leeds PF, Fleisig AJ, Prokipcak RD \& Ross J 1998 The c-myc coding region determinant-binding protein: a member of a family of $\mathrm{KH}$ domain RNA-binding proteins. Nucleic Acids Research 26 5036-5044.

Gu L, Shigemasa K \& Ohama K 2004 Increased expression of IGF II mRNA-binding protein $1 \mathrm{mRNA}$ is associated with an advanced clinical stage and poor prognosis in patients with ovarian cancer. International Journal of Oncology 24 671-678.

Hansen TV, Hammer NA, Nielsen J, Madsen M, Dalbaeck C, Wewer UM, Christiansen J \& Nielsen FC 2004 Dwarfism and impaired gut development in insulin-like growth factor II mRNA-binding protein 1-deficient mice. Molecular and Cellular Biology 24 4448-4464.

Havin L, Git A, Elisha Z, Oberman F, Yaniv K, Schwartz SP, Standart N \& Yisraeli JK 1998 RNA-binding protein conserved in both microtubule- and microfilament-based RNA localization. Genes \& Development 12 1593-1598.

Leeds P, Kren BT, Boylan JM, Betz NA, Steer CJ, Gruppuso PA \& Ross J 1997 Developmental regulation of CRD-BP, an RNA-binding protein that stabilizes c-myc mRNA in vitro. Oncogene $\mathbf{1 4}$ 1279-1286.

Mori H, Sakakibara S, Imai T, Nakamura Y, lijima T, Suzuki A, Yuasa Y, Takeda M \& Okano H 2001 Expression of mouse igf2 mRNAbinding protein 3 and its implications for the developing central nervous system. Journal of Neuroscience Research 64 132-143.

Mueller-Pillasch F, Pohl B, Wilda M, Lacher U, Beil M, Wallrapp C, Hameister H, Knochel W, Adler G \& Gress TM 1999 Expression of the highly conserved RNA binding protein $\mathrm{KOC}$ in embryogenesis. Mechanisms of Development 88 95-99.

Nielsen FC, Nielsen J \& Christiansen J 2001 A family of IGF-II mRNA binding proteins (IMP) involved in RNA trafficking. Scandinavian Journal of Clinical Laboratory Investigation Supplement 234 93-99.

Nielsen FC, Nielsen J, Kristensen MA, Koch G \& Christiansen J 2002 Cytoplasmic trafficking of IGF-II mRNA-binding protein by conserved KH domains. Journal of Cell Science 115 2087-2097.

Nielsen J, Adolph SK, Rajpert-De Meyts E, Lykke-Andersen J, Koch G, Christiansen J \& Nielsen FC 2003 Nuclear transit of human zipcode-binding protein IMP1. Biochemical Journal 376 383-391.

Nielsen J, Christiansen J, Lykke-Andersen J, Johnsen AH, Wewer UM \& Nielsen FC 1999 A family of insulin-like growth factor II mRNAbinding proteins represses translation in late development. Molecular and Cellular Biology 19 1262-1270.
Nielsen J, Kristensen MA, Willemoes M, Nielsen FC \& Christiansen J 2004 Sequential dimerization of human zipcode-binding protein IMP1 on RNA: a cooperative mechanism providing RNP stability. Nucleic Acids Research 32 4368-4376.

Oleynikov Y \& Singer RH 2003 Real-time visualization of ZBP1 association with beta-actin mRNA during transcription and localization. Current Biology 13 199-207.

Pesce M, Wang X, Wolgemuth DJ \& Scholer H 1998 Differential expression of the Oct-4 transcription factor during mouse germ cell differentiation. Mechanisms of Development 71 89-98.

Rajpert-De Meyts E, Jacobsen GK, Bartkova J, Aubry F, Samson M, Bartek J \& Skakkebaek NE 2003a The immunohistochemical expression pattern of Chk2, p53, p19INK4d, MAGE-A4 and other selected antigens provides new evidence for the premeiotic origin of spermatocytic seminoma. Histopathology 42 217-226.

Rajpert-De Meyts E, Bartkova J, Samson M, Hoei-Hansen CE, Frydelund-Larsen L, Bartek J \& Skakkebaek NE 2003b The emerging phenotype of the testicular carcinoma in situ germ cell. Apmis 111 267-278; discussion 278-279.

Rorth M, Rajpert-De Meyts E, Andersson L, Dieckmann KP, Fossa SD, Grigor KM, Hendry WF, Herr HW, Looijenga LH \& Oosterhuis JW et al. 2000 Carcinoma in situ in the testis. Scandinavian Journal of Urology and Nephrology Supplement 166-186.

Ross AF, Oleynikov Y, Kislauskis EH, Taneja KL \& Singer RH 1997 Characterization of a beta-actin mRNA zipcode-binding protein. Molecular and Cellular Biology 17 2158-2165.

Ruggiu M, Speed R, Taggart M, McKay SJ, Kilanowski F, Saunders P, Dorin J \& Cooke HJ 1997 The mouse Dazla gene encodes a cytoplasmic protein essential for gametogenesis. Nature 389 73-77.

Runge S, Nielsen FC, Nielsen J, Lykke-Andersen J, Wewer UM \& Christiansen J 2000 H19 RNA binds four molecules of insulin-like growth factor II mRNA-binding protein. Journal of Biological Chemistry $27529562-29569$.

Schumacher JM, Lee K, Edelhoff S \& Braun RE 1995 Spnr, a murine RNA-binding protein that is localized to cytoplasmic microtubules. Journal of Cell Biology 129 1023-1032.

Skakkebaek NE, Berthelsen JG, Giwercman A \& Muller J 1987 Carcinoma-in situ of the testis: possible origin from gonocytes and precursor of all types of germ cell tumours except spermatocytoma. International Journal of Andrology 10 19-28.

Tannahill D \& Melton DA 1989 Localized synthesis of the Vg1 protein during early Xenopus development. Development $\mathbf{1 0 6}$ 775-785.

Tessier CR, Doyle GA, Clark BA, Pitot HC \& Ross J 2004 Mammary tumor induction in transgenic mice expressing an RNA-binding protein. Cancer Research 64 209-214.

Thomsen GH \& Melton DA 1993 Processed Vg1 protein is an axial mesoderm inducer in Xenopus. Cell 74 433-441.

Wagner M, Kunsch S, Duerschmied D, Beil M, Adler G, Mueller F \& Gress TM 2003 Transgenic overexpression of the oncofetal RNA binding protein $\mathrm{KOC}$ leads to remodeling of the exocrine pancreas. Gastroenterology 124 1901-1914.

Wang T, Fan L, Watanabe Y, McNeill PD, Moulton GG, Bangur C, Fanger GR, Okada M, Inoue Y \& Persing DH et al. 2003 L523S, an RNA-binding protein as a potential therapeutic target for lung cancer. British Journal of Cancer 88 887-894.

Weeks DL \& Melton DA 1987 A maternal mRNA localized to the vegetal hemisphere in Xenopus eggs codes for a growth factor related to TGF-beta. Cell 51 861-867.

Yang J, Chennathukuzhi V, Miki K, O'Brien DA \& Hecht NB 2003 Mouse testis brain RNA-binding protein/translin selectively binds to the messenger RNA of the fibrous sheath protein glyceraldehyde 3 -phosphate dehydrogenase-S and suppresses its translation in vitro. Biology of Reproduction 68 853-859.

Yaniv K \& Yisraeli JK 2002 The involvement of a conserved family of RNA binding proteins in embryonic development and carcinogenesis. Gene 287 49-54. 
Yaniv K, Fainsod A, Kalcheim C \& Yisraeli JK 2003 The RNA-binding protein Vg1 RBP is required for cell migration during early neural development. Development 130 5649-5661.

Yisraeli JK 2005 VICKZ proteins: a multi-talented family of regulatory RNA-binding proteins. Biology of the Cell 97 87-96.

Zhang JY, Chan EK, Peng XX \& Tan EM 1999a A novel cytoplasmic protein with RNA-binding motifs is an autoantigen in human hepatocellular carcinoma. Journal of Experimental Medicine 189 $1101-1110$.

Zhang Q, Yaniv K, Oberman F, Wolke U, Git A, Fromer $\mathbf{M}$, Taylor WL, Meyer D, Standart N \& Raz E et al. 1999b Vg1 RBP intracellular distribution and evolutionarily conserved expression at multiple stages during development. Mechanisms of Development $88101-106$.

Received 25 January 2005

First decision 18 March 2005

Revised manuscript received 14 April 2005

Accepted 23 May 2005 